Research Article

\title{
The Influence of Dosing Modes of Coagulate on Arsenic Removal
}

\author{
Zhibin Zhang, Jinxiang Li, Cuizhen Sun, Yanhao Zhang, Lilong Huang, and Meng Wang \\ School of Municipal and Environmental Engineering, Shandong Jianzhu University, No. 1000 Fengming Road, Jinan 250101, China \\ Correspondence should be addressed to Yanhao Zhang; sdzyh66@126.com
}

Received 24 April 2014; Revised 14 June 2014; Accepted 17 June 2014; Published 3 July 2014

Academic Editor: Ana Moldes

Copyright (C) 2014 Zhibin Zhang et al. This is an open access article distributed under the Creative Commons Attribution License, which permits unrestricted use, distribution, and reproduction in any medium, provided the original work is properly cited.

\begin{abstract}
Three different dosing modes, including one single dosing mode and two sequential dosing modes, were applied in high-arsenic contaminated water treatment. The results illustrated that the As (V) soluble and the As (V) nonspecifically sorbed were the insignificant species from $\mathrm{Fe}$-As $(\mathrm{V})$ samples in the sequential dosing mode, while they were higher in the single dosing mode. However, it could be further concluded that the mobility of the Fe-As (V) in sequential dosing mode was greater than that in single dosing mode. Besides, the main arsenic speciation governing the arsenic-borne coagulates was the As (V) associated with poorly crystalline hydrous oxides of Fe in sequential or single dosing mode. Moreover, the particle size distribution analysis indicated that the sequential dosing mode was more prevalent in neutralizing and adsorbing the As (V) compared with the single dosing mode. In the FT-IR spectra, the presence of arsenic was highlighted by a well resolved band at $825-829 \mathrm{~cm}^{-1}$. The positions of the As-O stretching vibration bands were shifted gradually as the dosing mode changed from the single to the sequential. This result could be related to the distribution of arsenic speciation in different dosing modes.
\end{abstract}

\section{Introduction}

Arsenic is a common element found in naturally contaminated groundwater and surface water in many countries [1]. It is one of the most dangerous pollutants, owing to the toxicity, odorlessness, and nearly tastelessness [2-4]. The chronic and acute poisoning of As is related positively to the exposure to elevated concentrations, threatening groundwater safety, agriculture irrigation, and aquatic ecosystems $[5,6]$.

In the natural environment, arsenic exists in different oxidation states and various forms, for example, +V (arsenate), +III (arsenite), 0 (arsenic), and -III (arsine) [7]. It has been determined that the arsenic toxicity depended on the speciation [8]. Generally, inorganic arsenic species are more toxic than organic ones, while, among the inorganic arsenic species, arsenite (As (III)) is usually more toxic than arsenate (As (V)) [9]. Since As (III) species show greater mobility than those of As (V), they are more harmful to human health $[10,11]$. Considering the high toxicity, the World Health Organization (WHO) has decreased the maximum contaminant level of arsenic in drinking water from 50 to $10 \mu \mathrm{g} / \mathrm{L}[12]$.
It has been widely acknowledged that arsenic pollution associated with the geochemical environment such as volcanic deposits, geothermal sources, and arsenic-containing rocks [13-15]. Besides, anthropogenic activities, such as mining, fossil fuels burning, ores smelting, chemical wood preservatives, and arsenical pesticides, also release high concentrations of arsenic to the environment directly, which have attracted attentions worldwide [16-18].

In high-arsenic aquatic system, the partition and release of arsenic are of serious concern owing to the reaction on water-mineral interfaces [1]. Conventionally, there have been several methods for arsenic removals, including coagulation (precipitation) [19, 20], adsorption [21-23], ion exchange [24], membrane filtration [25], bioremediation [26], and electrochemical treatments $[27,28]$. Of all these methods, coagulation and flocculation were the most cost-effective ways for high-arsenic water [29]. In the coagulation process, arsenic ions (arsenate or arsenite) attach on the coagulants and precipitate with added ferric or aluminum ions [30, 31]. Then, the coagulants are separated through filtration, eliminating arsenic from arsenic-polluted water [32]. Although most researchers deduced that the coagulation efficiency was 
TABle 1: Processes of the sequential extraction.

\begin{tabular}{lccc}
\hline Step & As $(\mathrm{V})$ speciation & Extraction reagent & Extraction method \\
\hline I & Soluble & $50 \mathrm{~mL}$ of distilled water $(\mathrm{pH} 6.5)$ & Shaken for $2 \mathrm{~h}$ at $25^{\circ} \mathrm{C}$ \\
II & Nonspecifically sorbed & $50 \mathrm{~mL}$ of $0.05 \mathrm{~mol} / \mathrm{L}\left(\mathrm{NH}_{4}\right)_{2} \mathrm{SO}_{4}$ & Shaken for $4 \mathrm{~h} \mathrm{at} 20^{\circ} \mathrm{C}$ \\
III & Specifically sorbed & $50 \mathrm{~mL}$ of $0.05 \mathrm{~mol} / \mathrm{L} \mathrm{NH}_{4} \mathrm{H}_{2} \mathrm{PO}_{4}$ & Shaken for $16 \mathrm{~h}$ at $20^{\circ} \mathrm{C}$ \\
IV & Poorly crystalline hydrous oxides of $\mathrm{Fe}$ & $50 \mathrm{~mL} \mathrm{of} 0.2 \mathrm{~mol} / \mathrm{L} \mathrm{NH}_{4}^{+}$-oxalate buffer $(\mathrm{pH} \mathrm{3.25)}$ & Shaken for $4 \mathrm{~h}$ in dark at $20^{\circ} \mathrm{C}$ \\
V & Well-crystallized hydrous oxides of Fe & $50 \mathrm{~mL} \mathrm{of} 0.2 \mathrm{M} \mathrm{NH}_{4}^{+}$-oxalate buffer $+0.1 \mathrm{M}$ ascorbic & Shaken for $0.5 \mathrm{~h}$ at $96^{\circ} \mathrm{C}$ \\
\hline
\end{tabular}

influenced by various parameters, fewer reported the effect of the dosing mode. In addition, little about the forms of arsenic in arsenic-borne coagulates was investigated, which could assist in elucidating the coagulation mechanism.

The objectives of this study were as follows.

(1) Investigate the arsenic removal efficiency with ferric chloride dosed in different modes.

(2) Determine the mechanisms of ferric chloride interacting with arsenate in different sequential dosing modes.

(3) Investigate the surface complex formed on ferric chloride in different sequential dosing modes with Fourier transform infrared (FT-IR) spectroscopy.

\section{Materials and Methods}

2.1. Materials. All solutions were prepared with doubledeionized water. The high-arsenic water $(100 \mathrm{mg} / \mathrm{L})$ was prepared by dissolving disodium hydrogen arsenate heptahydrate $\left(\mathrm{Na}_{2} \mathrm{HAsO}_{4} \cdot 7 \mathrm{H}_{2} \mathrm{O}\right.$ purity $\left.>98.5 \%\right)$ in Milli-Q water. Besides, all vessels were cleaned with detergent, soaked in $10 \%$ $\mathrm{HNO}_{3}$ for $24 \mathrm{~h}$, and rinsed three times with double-deionized water. The $\mathrm{pH}$ electrode was calibrated with either sodium hydroxide or hydrochloric acid. All chemicals used in the experiments were of reagent grade.

2.2. Batch Tests. All batch tests were performed at constant temperature $\left(25 \pm 1^{\circ} \mathrm{C}\right)$. Conventional jar-test apparatus (MY3000-6M, Wuhan, China), equipped with $1.0 \mathrm{~L}$ plexiglass beakers, were used for the coagulation study. Certain amounts of ferric chloride (FC: $\mathrm{FeCl}_{3} \cdot 6 \mathrm{H}_{2} \mathrm{O}$ ) were dosed in three different dosing modes as shown in Figure 1.

Mode A (single dosing): $500 \mathrm{mg}$ of FC was added during rapid mixing (300 $\mathrm{rpm}$ for $1 \mathrm{~min}$ ), followed by slow stirring at $100 \mathrm{rpm}$ for $19 \mathrm{~min}$, and further slow stirring at $50 \mathrm{rpm}$ for $10 \mathrm{~min}$.

Mode B (two-step sequential dosing): $400 \mathrm{mg}$ of FC was dosed in the first step under the same coagulation process in mode A, while $100 \mathrm{mg}$ of FC was used in the supernatant in the second step with the same coagulation process in mode A.

Mode C (three-step sequential dosing): under the same coagulation process, $300 \mathrm{mg}$ of FC was used in the first step, $100 \mathrm{mg}$ of FC was added in the supernatant of the first step in the second step, and $100 \mathrm{mg}$ of FC was dosed in the supernatant of the second step in the last step. The coagulation processes of the last steps were same as those of mode A.
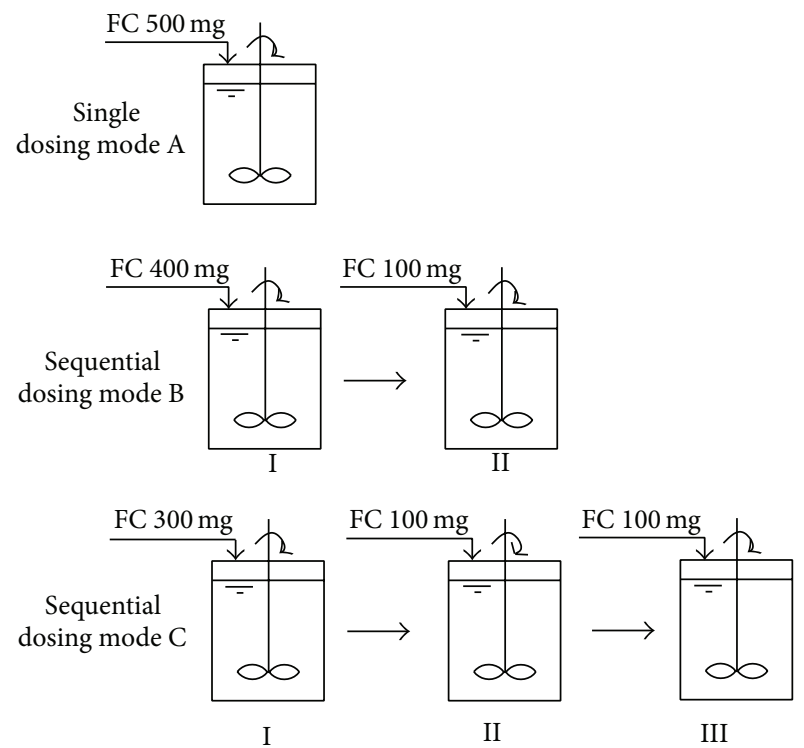

FIGURE 1: Dosing modes for the jar tests.

The $\mathrm{pH}$ of the solution was stabilized at desired values by adding $0.01 \mathrm{~mol} / \mathrm{L} \mathrm{HCl}$ and $\mathrm{NaOH}$ standard solutions. $10 \mathrm{~mL}$ of supernatant at $3 \mathrm{~cm}$ below the surface after sedimentation was sampled for the following batch experiments. All the supernatant samples were filtered through $0.22 \mu \mathrm{m}$ PTFE membranes (Millipore, US) for total arsenic determination with flame atomic absorption spectroscopy (AAS). The arsenic removal efficiency $(E)$ was calculated with

$$
E=\frac{C_{0}-C}{C_{0}} \times 100 \% \text {, }
$$

where $C_{0}$ and $C$ were initial arsenic concentration and effluent, respectively. The Fe-As (V) samples (sediment) were centrifuged at $8000 \mathrm{rpm}$ for $10 \mathrm{~min}$ and filtered through $0.22 \mu \mathrm{m}$ PTFE membranes (Millipore, US) for liquid/solid separation. Each sample was conducted in triplicate and mean values were reported.

2.3. Sequential Extraction. $2.0 \mathrm{~g}$ of Fe-As (V) samples was sampled from the batch experiments, following the methods of Daus et al. and Gao et al. [33, 34]. The binding information between arsenate and FC was investigated with a sequential extraction procedure [35]. Table 1 shows the details of the five-step extraction procedure. 


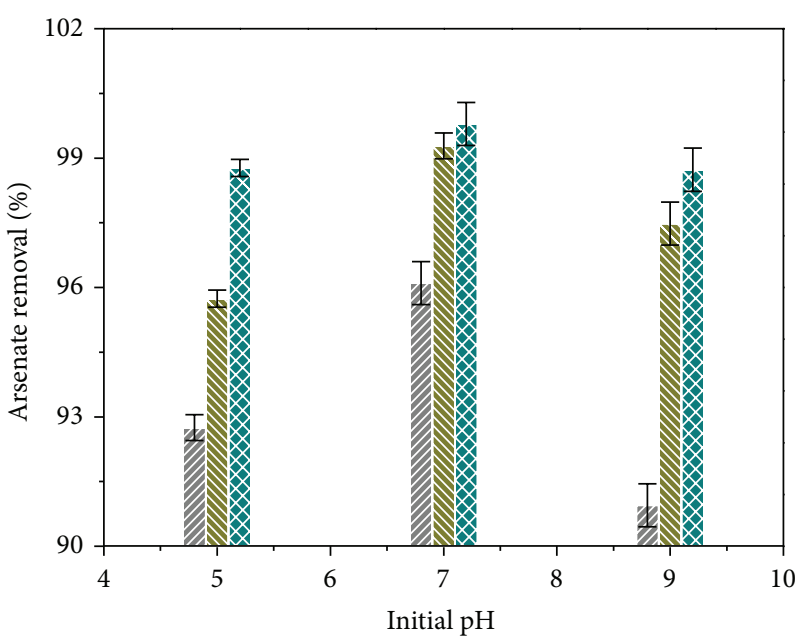

VIIS Mode A

niv Mode B

XXX Mode C

Figure 2: Arsenic removal efficiencies in different dosing modes. (Mode A: single-step dosing; Mode B: two-step sequential dosing; Mode C: three-step sequential dosing).

All supernatant samples were taken at $3 \mathrm{~cm}$ below the surface of the settled mixture and filtered through $0.22 \mu \mathrm{m}$ PTFE membranes (Millipore, US) before total arsenic by flame determination with atomic absorption spectroscopy (Perkin Elmer Aanalyst A300, Beijing, China). Each test was triplicate to guarantee the analysis quality.

2.4. Particle Size Distribution. Malvern Mastersizer 2000 (Malvern Co., Worcester, England) was used to analyze the size distribution of coagulant particles. The Malvern Mastersizer 2000 consisted of a $2 \mathrm{~mW} \mathrm{He-Ne} \mathrm{laser}(\lambda=$ $632.8 \mathrm{~nm}$ ) as the light source, optic lens, and photo-sensitive detectors. Each measurement was triplicate to guarantee the analysis quality.

2.5. FT-IR Spectroscopy. To investigate the interaction between As (V) and FC, Fourier transformed infrared (FT-IR) spectroscopy was used to characterize arsenic-borne coagulates sorption in different dosing modes. All the samples were prepared under the following method: the sediment samples from the coagulation experiments were dried to solids at $40^{\circ} \mathrm{C}$ and stored in a desiccator filled with silica gel at room temperature; the dried samples were mixed with $200 \mathrm{mg} \mathrm{KBr}$ and heated in an oven $\left(130^{\circ} \mathrm{C}\right)$ for at least $24 \mathrm{~h}$; the pellets for FT-IR analysis were made of $90 \mathrm{mg}$ of this mixture. The FT-IR spectra were recorded with a Bruker IFS55 spectrophotometer at room temperature within the range of $4000-400 \mathrm{~cm}^{-1}$ with 200 scans collected at $4 \mathrm{~cm}^{-1}$ resolution $[1,33,34]$.

\section{Results and Discussion}

3.1. The Effect of Dosing Modes on Arsenic Removal. The influence of $\mathrm{pH}$ on coagulation has been well investigated

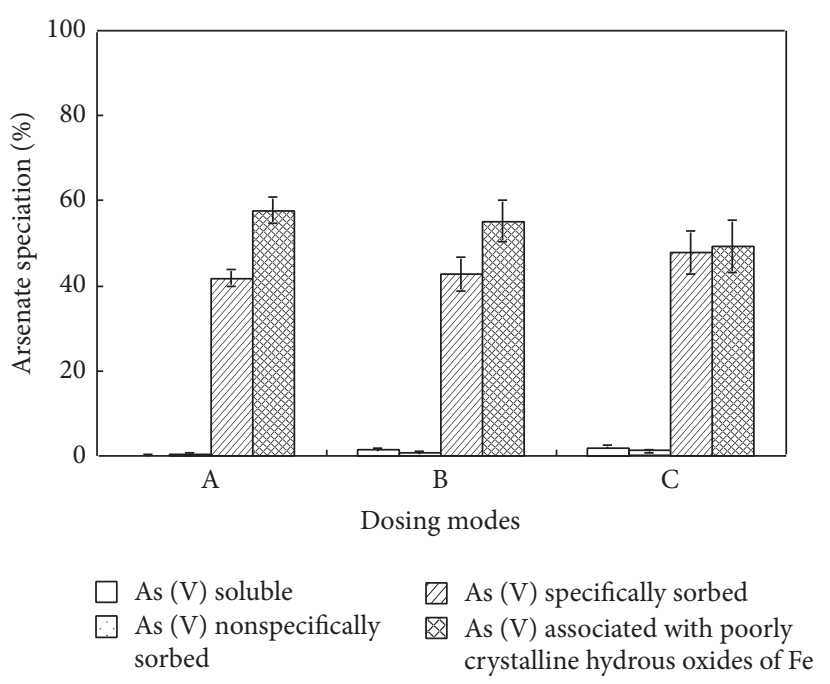

Figure 3: Percentage of As (V) extracted with a sequential extraction procedure from the Fe-As $(\mathrm{V})$ samples in the different dosing modes $\left(\mathrm{pH}_{\text {Initial }}=7.0\right)$.

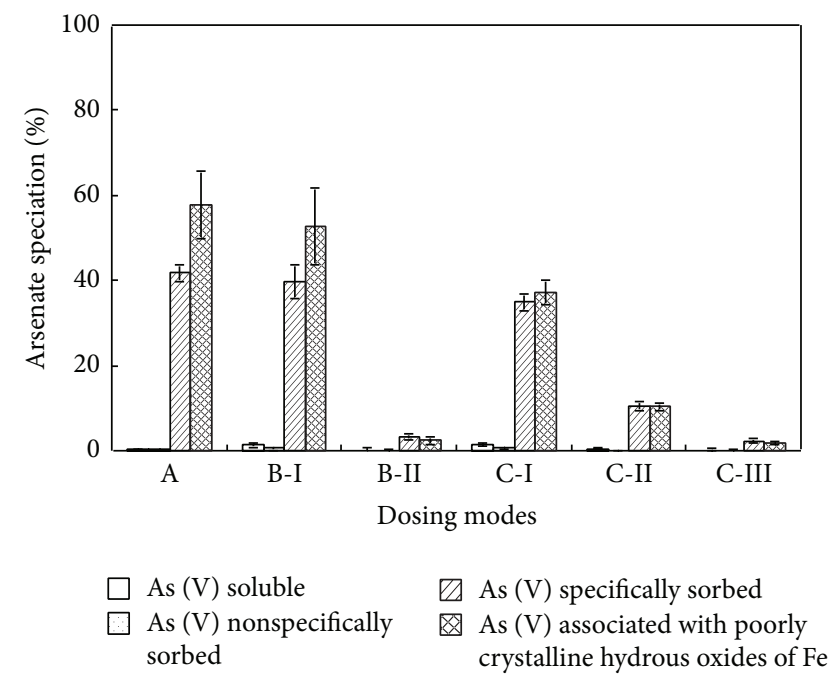

FIgURE 4: Percentage of As (V) extracted with a sequential extraction procedure from the Fe-As $(\mathrm{V})$ samples in different batches of dosing modes $\left(\mathrm{pH}_{\text {Initial }}=7.0\right)$.

[36]. Previous studies have given the optimum $\mathrm{pH}$ range (4.5-8.0) for high-arsenic water ferric coagulations [29].

The distribution of $\mathrm{As}(\mathrm{V})$ hydroxide species as a function of $\mathrm{pH}$ demonstrated that $\mathrm{H}_{2} \mathrm{AsO}_{4}{ }^{-}$and $\mathrm{HAsO}_{4}{ }^{2-}$ are the dominant species at neutral $\mathrm{pH}$. This implied that both could be major existing forms of As in these batch experiments $[37,38]$.

Figure 2 shows the arsenic removal efficiencies in different dosing modes in the following order: the sequential dosing mode (Mode $\mathrm{C}>$ Mode $\mathrm{B}$ ) $>$ the single dosing mode (Mode A). The arsenic removal preferred the sequential dosing mode to the single dosing mode.

3.2. Speciation Analysis. The arsenic-borne coagulates were treated following the sequential extraction method to study 

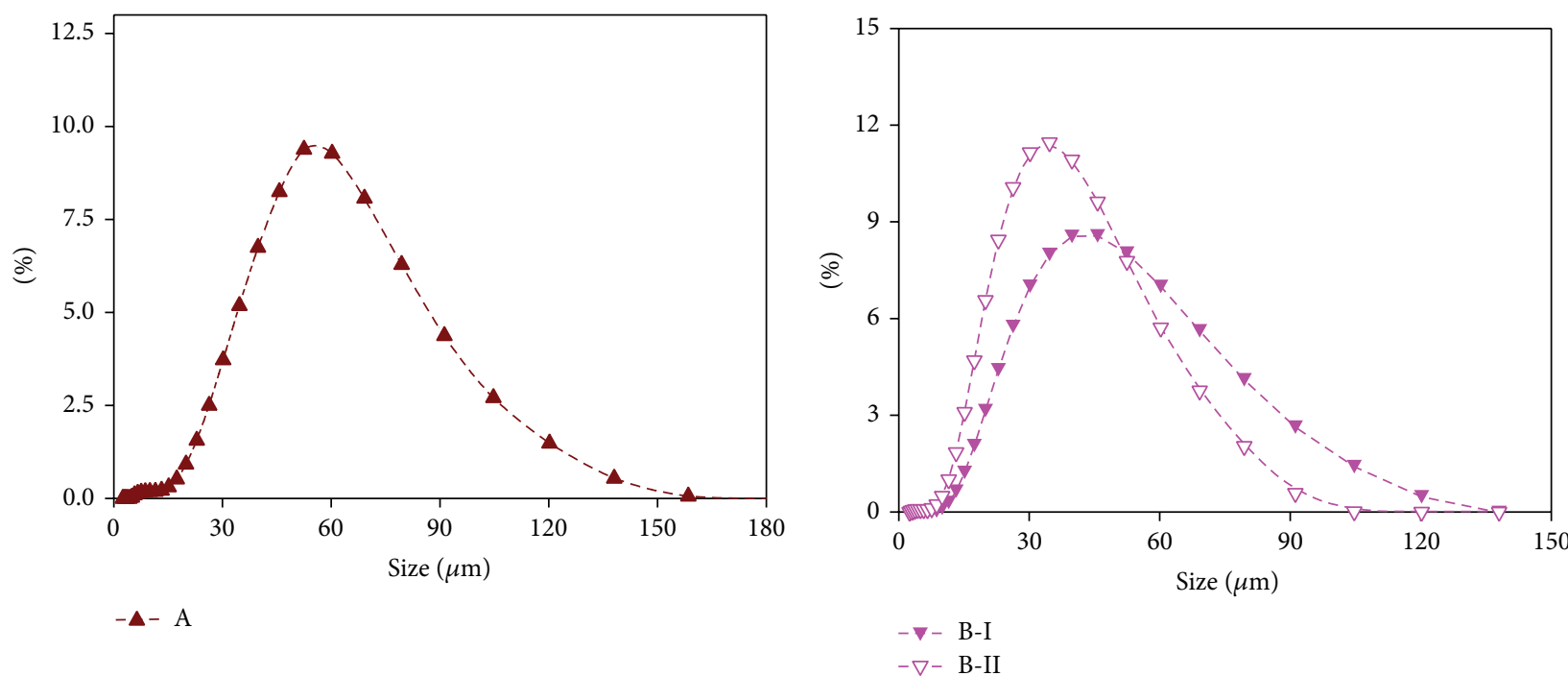

(a)

(b)

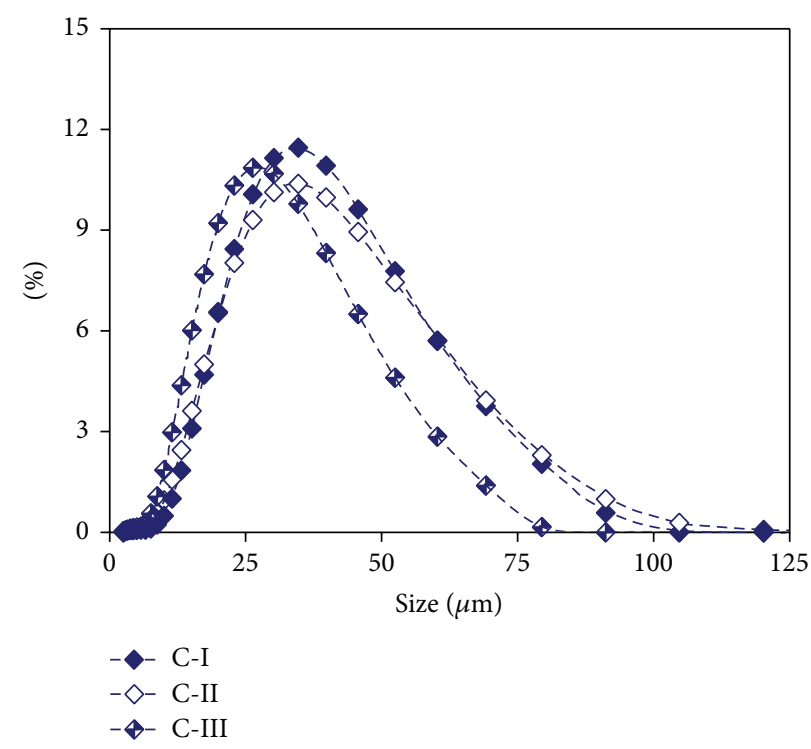

(c)

FIGURE 5: Variations of the size distribution with the Fe-As $(\mathrm{V})$ samples in different dosing modes $\left(\mathrm{pH}_{\text {Initial }}=7.0\right)$.

the arsenic removal mechanisms in different dosing modes [35].

Figure 3 shows that, in Step I, less than $2 \%$ of the arsenicborne coagulates were extracted for Mode $\mathrm{C}$ more than that for Mode B. For Mode A, this number was close to zero. In Step II, the percentage of arsenate extracted, associated with the relatively exchangeable fractions, such as As (V) bounded with outer-sphere complex, ascended from Mode A to Mode C. The numbers from Step III and Step IV were higher than $90 \%$ of the arsenate adsorbed for all three dosing modes, which represented the specifically sorbed As (V) and amorphous crystalline hydrous oxides of Fe, respectively.

Figure 3 showed that the order of the As (V) specifically sorbed was Mode A > Mode B > Mode C while the order of the As (V) associated with amorphous and poorly crystalline hydrous oxides of Fe was Mode C > Mode B > Mode A. Both As species would not be expected to be easily released under natural conditions. Besides, there was no fraction associated with well-crystallized hydrous oxides of Fe (Step V).

The five-step sequential extraction of As (V) from the FeAs (V) materials sampled from each dosing step (A, B-I, B-II, $\mathrm{C}-\mathrm{I}, \mathrm{C}-\mathrm{II}$, and C-III) was given in Figure 4. In the three modes (A, B, and $\mathrm{C}$ ), the As (V) was slightly soluble or physically exchangeable, once bound to the coagulant surface, and the As (V) specifically sorbed and associated with amorphous crystalline hydrous oxides of Fe were the dominant species (Steps III and IV). The main mechanism of arsenic removal with FC was a chemisorption process, involving the formation of inner-sphere surface complexes and low-solubility minerals (scorodite). The fact that the fractions of the As (V) 


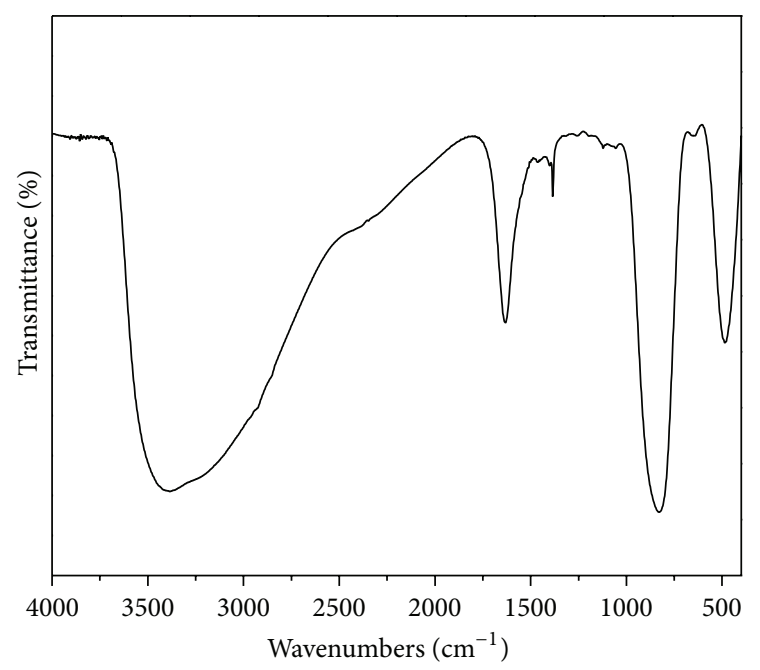

A

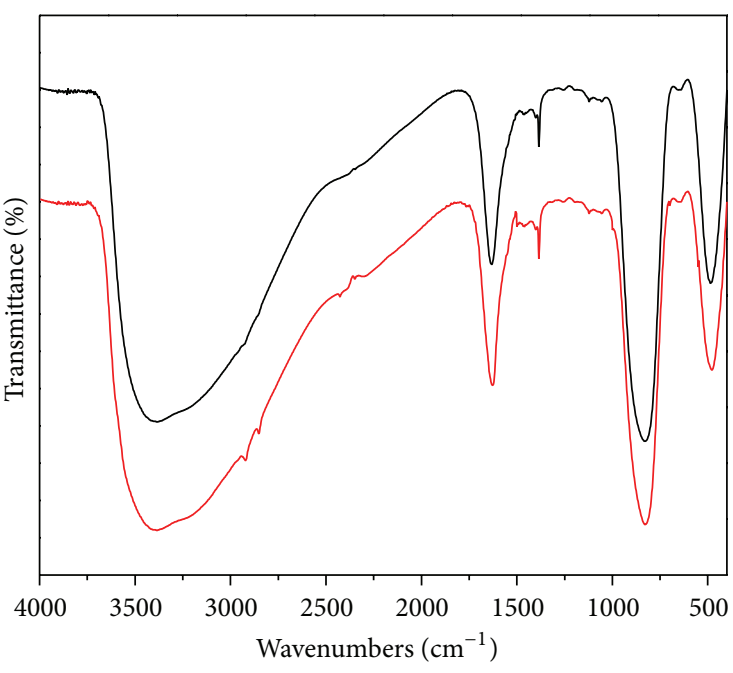

- B-I

(a)

(b)

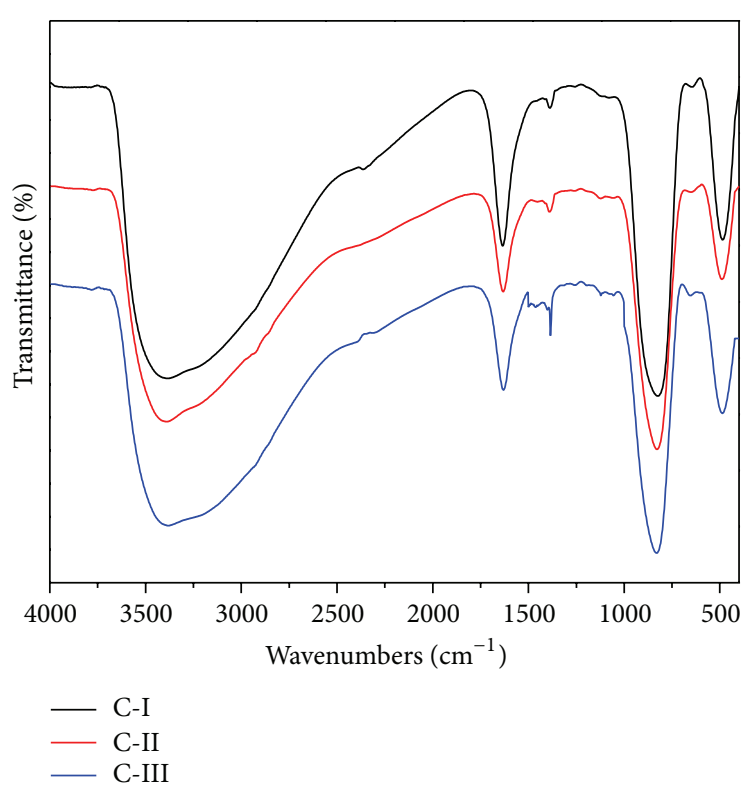

(c)

Figure 6: FT-IR spectra of the Fe-As (V) samples in different dosing modes (pH 7).

soluble and nonspecifically sorbed in sequential dosing mode were higher than those in single dosing mode means that the arsenic-borne coagulates of the sequential dosing modes were more environmentally hazardous.

3.3. Particle Size Distribution Analysis. The adsorption rate mainly depended on the radius of particles [39]. Figure 5 displayed the size distribution of the arsenic-borne coagulates in the different dosing steps (A, B-I, B-II, C-I, C-II, and $\mathrm{C}$-III). All of arsenic-borne coagulates were fine particles, ranging between 2.5 and $160 \mu \mathrm{m}$. The particles showed that the different average size in different dosing modes followed the following order: Mode A > Mode B (B-I > B-II) > Mode
C (C-I > C-II > C-III). The As (V) nonspecifically sorbed and soluble of Mode $\mathrm{C}$ was approximately 3.0\% lower than Mode B and Mode A. It is likely attributed to the changeable surface structure of the particles. Generally, the specific surface area increased with size decreasing and the smaller particles physically sorbed more As (V). Consequently, it could be concluded that the surface structure of the arsenicborne coagulates favored the neutralization and adsorption of the As (V) and two sequential dosing modes were more prevalent than the single one.

3.4. FT-IR Spectra Analysis. FT-IR spectra of arsenate sorbed on the coagulant samples from three dosing modes 
were showed in Figure 6. In the whole range scanning (400-4000 $\mathrm{cm}^{-1}$ ), a strong band was present in the hydroxyl stretching region at $3400-3300 \mathrm{~cm}^{-1}$, which is likely attributed to the presence of $\mathrm{H}_{2} \mathrm{O}$ in the Fe-As (V) samples $[40,41]$. In the spectra a band at $1630 \mathrm{~cm}^{-1}$ was also found, resulting from the water $\mathrm{O}-\mathrm{H}$ bending mode [42]. For all spectra, an adsorbed peak due to stretching vibrations of $\mathrm{Fe}-\mathrm{O}$ bond was present approximately at $490 \mathrm{~cm}^{-1}$ [41]. Additionally, there was one well resolved band, peaked at $825-829 \mathrm{~cm}^{-1}$, owing to the As-O stretching vibration of the As-O-Fe coordination of the ferric arsenate (i.e., scorodite) and the surface complex (i.e., protonated $\mathrm{FeO}_{2} \mathrm{As}(\mathrm{O})(\mathrm{OH})^{-}$ and unprotonated $\mathrm{FeO}_{2} \mathrm{As}(\mathrm{O})_{2}{ }^{2-}$ forms) on the precipitates [35]. This demonstrated that the main mechanism of the arsenic removal was a chemisorption process, which matched well with the speciation analysis.

\section{Conclusion}

The experimental results showed that arsenic removal efficiency of the sequential dosing mode was higher than the single dosing mode. The sequential extraction procedure, applied to Fe-As (V) samples exchanged with arsenate, showed that the As (V) specifically sorbed associated with amorphous crystalline hydrous oxides of Fe were the dominant species (over 90\%) from the Fe-As (V) samples in different dosing modes. The main mechanism of the arsenic removal with FC was a chemisorption process, matching with the information obtained with FT-IR spectra analysis. The particle size distribution analysis illustrated that the surface structure of the arsenic-borne coagulates favored the neutralization and adsorption of As (V) and the sequential dosing mode was prevalent, compared with the single one.

\section{Conflict of Interests}

The authors declare that there is no conflict of interests regarding the publication of this paper.

\section{Acknowledgments}

The authors thank the Department of Environmental Protection of Shandong Province (no. SDHBPJ-ZB-09) and Natural Science Foundation of Shandong Province for providing the financial support (no. BS2013HZ028).

\section{References}

[1] K. Müller, V. S. T. Ciminelli, M. S. S. Dantas, and S. Willscher, "A comparative study of As(III) and As(V) in aqueous solutions and adsorbed on iron oxy-hydroxides by Raman spectroscopy," Water Research, vol. 44, no. 19, pp. 5660-5672, 2010.

[2] J. Youngran, M. FAN, J. Van Leeuwen, and J. F. Belczyk, "Effect of competing solutes on arsenic (V) adsorption using iron and aluminum oxides," Journal of Environmental Sciences, vol. 19, no. 8, pp. 910-919, 2007.

[3] P. Castaldi, M. Silvetti, S. Enzo, and P. Melis, "Study of sorption processes and FT-IR analysis of arsenate sorbed onto red muds (a bauxite ore processing waste)," Journal of Hazardous Materials, vol. 175, no. 1-3, pp. 172-178, 2010.

[4] J. C. Ng, "Environmental contamination of arsenic and its toxicological impact on humans," Environmental Chemistry, vol. 2, no. 3, pp. 146-160, 2005.

[5] S. Wang and C. N. Mulligan, "Speciation and surface structure of inorganic arsenic in solid phases: a review," Environment International, vol. 34, no. 6, pp. 867-879, 2008.

[6] P. Bhattacharya, A. H. Welch, K. G. Stollenwerk, M. J. McLaughlin, J. Bundschuh, and G. Panaullah, "Arsenic in the environment: Biology and Chemistry," Science of the Total Environment, vol. 379, no. 2-3, pp. 109-120, 2007.

[7] T. S. Y. Choong, T. G. Chuah, Y. Robiah, F. L. Gregory Koay, and I. Azni, "Arsenic toxicity, health hazards and removal techniques from water: an overview," Desalination, vol. 217, no. 1-3, pp. 139-166, 2007.

[8] V. K. Sharma and M. Sohn, "Aquatic arsenic: toxicity, speciation, transformations, and remediation," Environment International, vol. 35, no. 4, pp. 743-759, 2009.

[9] B. K. Mandal and K. T. Suzuki, "Arsenic round the world: a review," Talanta, vol. 58, no. 1, pp. 201-235, 2002.

[10] A. A. Meharg and J. Hartley-Whitaker, "Arsenic uptake and metabolism in arsenic resistant and nonresistant plant species," New Phytologist, vol. 154, no. 1, pp. 29-43, 2002.

[11] D. Lièvremont, P. N. Bertin, and M. C. Lett, "Arsenic in contaminated waters: biogeochemical cycle, microbial metabolism and biotreatment processes," Biochimie, vol. 91, no. 10, pp. 1229-1237, 2009.

[12] X.-H. Guan, T. Su, and J. Wang, "Quantifying effects of $\mathrm{pH}$ and surface loading on arsenic adsorption on NanoActive alumina using a speciation-based model," Journal of Hazardous Materials, vol. 166, no. 1, pp. 39-45, 2009.

[13] A. H. Welch, M. S. Lico, and J. L. Hughes, "Arsenic in ground water of the western United States," Ground Water, vol. 26, no. 3, pp. 333-347, 1988.

[14] N. E. Korte and Q. Fernando, "A review of arsenic (III) in groundwater," Critical Reviews in Environmental Science and Technology, vol. 21, no. 1, pp. 1-39, 1991.

[15] F. N. Robertson, "Arsenic in ground-water under oxidizing conditions, south-west United States," Environmental Geochemistry and Health, vol. 11, no. 3-4, pp. 171-185, 1989.

[16] M. Bissen and F. H. Frimmel, "Arsenic-a review. Part I: occurrence, toxicity, speciation, mobility," Acta Hydrochimica et Hydrobiologica, vol. 31, no. 1, pp. 9-18, 2003.

[17] M. Bissen and F. H. Frimmel, "Arsenic-a review-part II: oxidation of arsenic and its removal in water treatment," Acta Hydrochimica et Hydrobiologica, vol. 31, no. 2, pp. 97-107, 2003.

[18] P. L. Smedley and D. G. Kinniburgh, "A review of the source, behaviour and distribution of arsenic in natural waters," Applied Geochemistry, vol. 17, no. 5, pp. 517-568, 2002.

[19] S. R. Wickramasinghe, B. Han, J. Zimbron, Z. Shen, and M. N. Karim, "Arsenic removal by coagulation and filtration: comparison of groundwaters from the United States and Bangladesh," Desalination, vol. 169, no. 3, pp. 231-244, 2004.

[20] J. G. Hering, P. Y. Chen, J. A. Wilkie, and M. Elimelech, "Arsenic removal from drinking water during coagulation," Journal of Environmental Engineering, vol. 123, no. 8, pp. 800-807, 1997.

[21] L. Wang, A. S. C. Chen, T. J. Sorg, and K. A. Fields, "Field evaluation of as removal by IX and AA," Journal-American Water Works Association, vol. 94, no. 4, pp. 161-173, 2002. 
[22] Y. Zhang, M. Yang, and X. Huang, "Arsenic(V) removal with a Ce(IV)-doped iron oxide adsorbent," Chemosphere, vol. 51, no. 9, pp. 945-952, 2003.

[23] I. A. Katsoyiannis and A. I. Zouboulis, "Removal of arsenic from contaminated water sources by sorption onto iron-oxide-coated polymeric materials," Water Research, vol. 36 , no. 20, pp. 51415155, 2002.

[24] E. Korngold, N. Belayev, and L. Aronov, "Removal of arsenic from drinking water by anion exchangers," Desalination, vol. 141, no. 1, pp. 81-84, 2001.

[25] Y. Sato, M. Kang, T. Kamei, and Y. Magara, "Performance of nanofiltration for arsenic removal," Water Research, vol. 36, no. 13, pp. 3371-3377, 2002.

[26] I. A. Katsoyiannis and A. I. Zouboulis, "Application of biological processes for the removal of arsenic from groundwaters," Water Research, vol. 38, no. 1, pp. 17-26, 2004.

[27] P. R. Kumar, S. Chaudhari, K. C. Khilar, and S. P. Mahajan, "Removal of arsenic from water by electrocoagulation," Chemosphere, vol. 55, no. 9, pp. 1245-1252, 2004.

[28] M. Arienzo, P. Adamo, J. Chiarenzelli, M. R. Bianco, and A. de Martino, "Retention of arsenic on hydrous ferric oxides generated by electrochemical peroxidation," Chemosphere, vol. 48, no. 10, pp. 1009-1018, 2002.

[29] S. Song, A. Lopez-Valdivieso, D. J. Hernandez-Campos, C. Peng, M. G. Monroy-Fernandez, and I. Razo-Soto, "Arsenic removal from high-arsenic water by enhanced coagulation with ferric ions and coarse calcite," Water Research, vol. 40, no. 2, pp. 364372,2006

[30] Y. S. Shen, "Study of arsenic removal from drinking water," Journal-American Water Works Association, vol. 65, no. 8, pp. 543-548, 1973

[31] J. G. Hering, P. Chen, J. A. Wilkie, M. Elimelech, and S. Liang, "Arsenic removal by ferric chloride," Journal of the American Water Works Association, vol. 88, no. 4, pp. 155-167, 1996.

[32] T. J. Sorg, "Treatment technology to meet the interim primary drinking water regulations for inorganics," American Water Works Association, vol. 70, no. 2, pp. 105-112, 1978.

[33] B. Daus, H. Weiß, and R. Wennrich, "Arsenic speciation in iron hydroxide precipitates," Talanta, vol. 46, no. 5, pp. 867-873, 1998.

[34] B. Gao, Y. Wang, Q. Yue, J. Wei, and Q. Li, “The size and coagulation behavior of a novel composite inorganic-organic coagulant," Separation and Purification Technology, vol. 62, no. 3, pp. 544-550, 2008.

[35] W. W. Wenzel, N. Kirchbaumer, T. Prohaska, G. Stingeder, E. Lombi, and D. C. Adriano, "Arsenic fractionation in soils using an improved sequential extraction procedure," Analytica Chimica Acta, vol. 436, no. 2, pp. 309-323, 2001.

[36] J. E. Gregor, C. J. Nokes, and E. Fenton, “Optimising natural organic matter removal from low turbidity waters by controlled $\mathrm{pH}$ adjustment of aluminium coagulation," Water Research, vol. 31, no. 12, pp. 2949-2958, 1997.

[37] A. Matilainen, M. Vepsäläinen, and M. Sillanpää, "Natural organic matter removal by coagulation during drinking water treatment: a review," Advances in Colloid and Interface Science, vol. 159, no. 2, pp. 189-197, 2010.

[38] H. Genç-Fuhrman, J. C. Tjell, and D. McConchie, "Adsorption of arsenic from water using activated neutralized red mud," Environmental Science and Technology, vol. 38, no. 8, pp. 24282434,2004
[39] J. Gregory, Particles in Water: Properties and Processes, CRC Press, 2004.

[40] P. Castaldi, M. Silvetti, L. Santona, S. Enzo, and P. Melis, "XRD, FTIR, and thermal analysis of bauxite ore-processing waste (red mud) exchanged with heavy metals," Clays and Clay Minerals, vol. 56, no. 4, pp. 461-469, 2008.

[41] H. D. Ruan, R. L. Frost, and J. T. Kloprogge, "The behavior of hydroxyl units of synthetic goethite and its dehydroxylated product hematite," Spectrochimica Acta A: Molecular and Biomolecular Spectroscopy, vol. 57, no. 13, pp. 2575-2586, 2001.

[42] Y. Jia, L. Xu, X. Wang, and G. P. Demopoulos, "Infrared spectroscopic and X-ray diffraction characterization of the nature of adsorbed arsenate on ferrihydrite," Geochimica et Cosmochimica Acta, vol. 71, no. 7, pp. 1643-1654, 2007. 

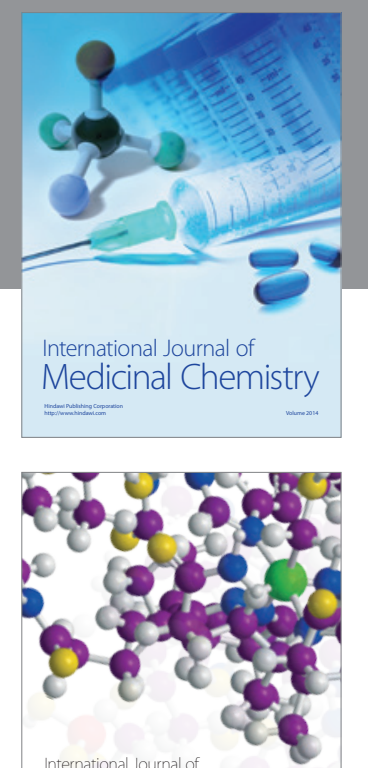

\section{Carbohydrate} Chemistry

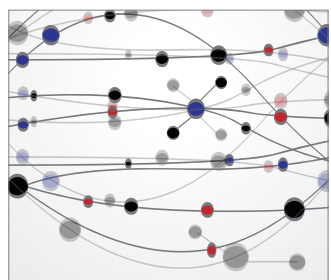

The Scientific World Journal
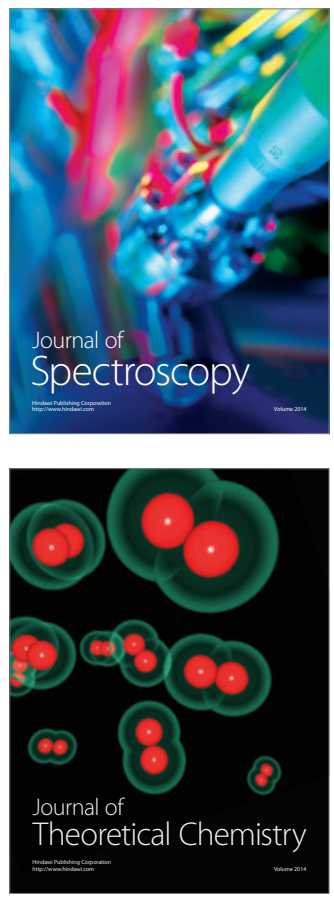
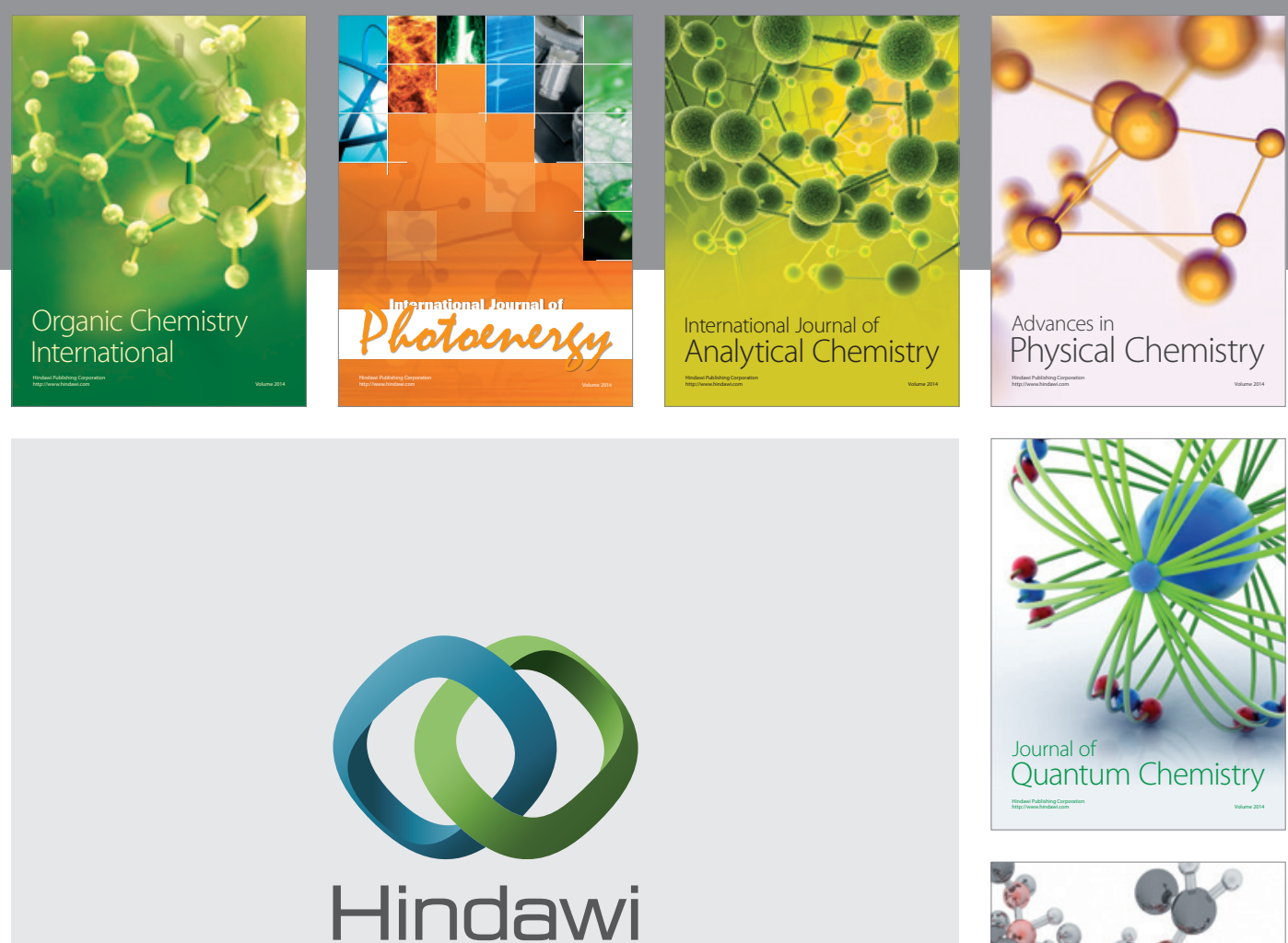

Submit your manuscripts at

http://www.hindawi.com

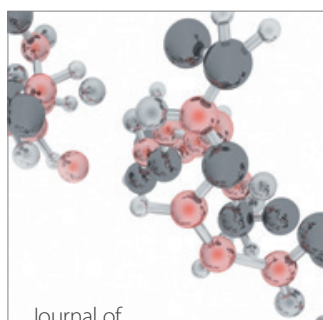

Analytical Methods

in Chemistry

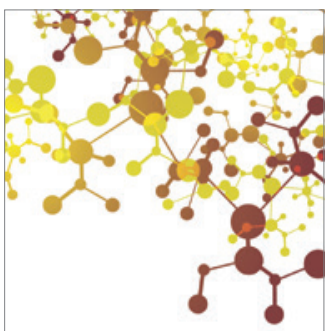

Journal of

Applied Chemistry

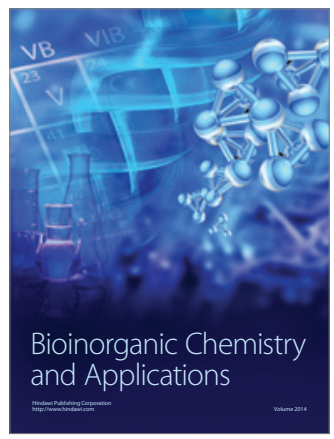

Inorganic Chemistry
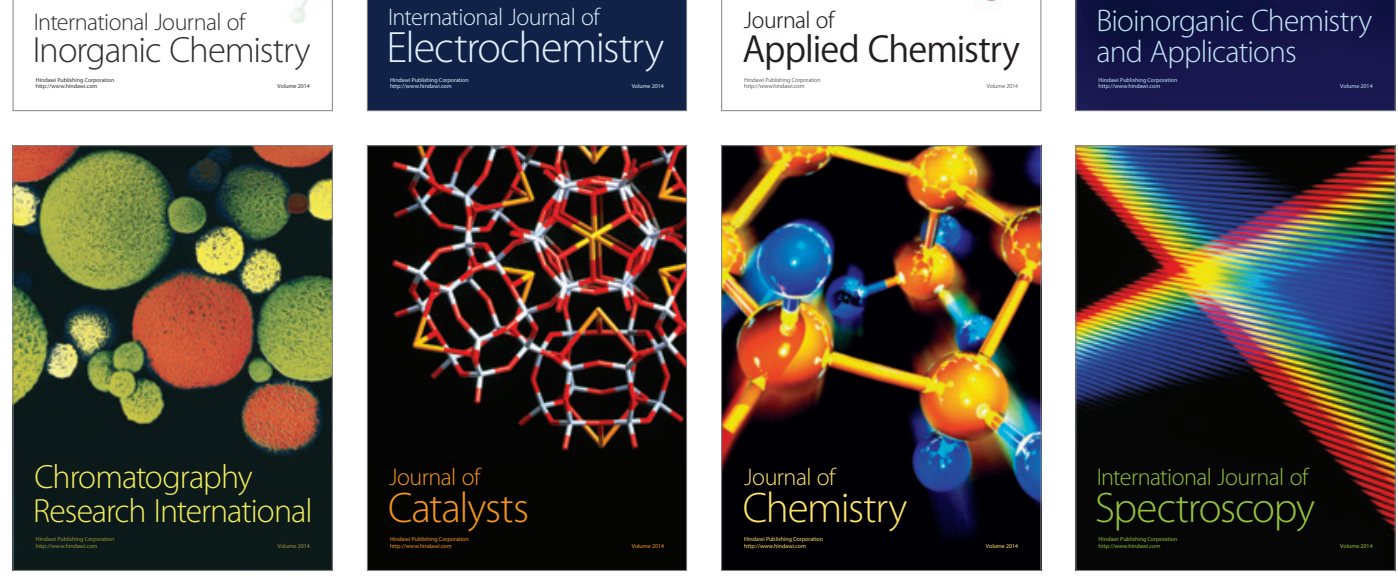